\title{
Evaluation of current policies on the use of unmanned aerial vehicles in Indian agriculture
}

\author{
Vijay Singh*, Muthukumar Bagavathiannan, Bhagirath Singh Chauhan and Samar Singh
}

Unmanned aerial vehicles (UAVS), commonly called 'drones', have enormous potential for technological advances in many sectors including agriculture. The recent revision in UAV policy by the Directorate General of Civil Aviation (DGCA), India, can impact the pace of research and development in machine vision capabilities in the country. Several other countries that have framed UAV policy previously, are continuously bringing changes to the existing framework to make it more user friendly. India can learn from those changes and bring out a comprehensive update to foster a broader application of these tools in agriculture. This policy review provides suggestions and solutions for increasing licensing centres, limiting UAV speed and weight for safer flights and including aerial pesticide applications in UAV permits to revolutionize the multibillion-dollar agriculture industry. This article has also examines the current UAV regulations in four other countries.

Keywords: DGCA, drone policy, precision agriculture, remote sensing, unmanned aerial vehicles.

UNMANNED AERIAL VEHICLES (UAVs) have emerged as the next generation tools for remote sensing and precision agriculture $^{1}$. The UAV platforms allow researchers to collect rapidly both spatial and temporal data at high resolutions ${ }^{2}$. These tools have the potential to transform soil and crop sciences research and agronomic management due to their unique footprint of measurement. Satellitebased remote sensing is limited in providing detailed measurements due to relatively poor resolutions (e.g. $2-15 \mathrm{~m} / \mathrm{pixel})^{3}$, compared to the high resolutions obtained with UAV-based imagery $(<2 \mathrm{~cm} / \text { pixel })^{3,4}$. As such, satellite-based imagery has limited utility for precision agriculture. Further, ground-based, field-scale tools currently available for precision agriculture ${ }^{5}$ are inefficient in bad weather and cannot be used in established crops due to potential disturbances to the crop plants ${ }^{6}$. UAVs with high spatial resolutions however, can cover large areas quickly without disturbing the crop. By combining UAV-based sensors with detailed point-scale measurements, high-quality maps can be generated at scales useful in precision agriculture for crop and weed management.

India is currently one of the fastest-growing markets for UAVs. India's UAV market will reach about US\$

\footnotetext{
Vijay Singh is in the Department of Soil and Crop Sciences, Texas A\&M University, USA; Muthukumar Bagavathiannan is in the Department of Soil and Crop Sciences, Texas A\&M University, USA; Bhagirath Singh Chauhan is in the Queensland Alliance for Agriculture and Food Innovation, The University of Queensland, Australia; Samar Singh is in the Department of Agronomy, CCS Haryana Agricultural University, Hisar 125 004, India.

*For correspondence. (e-mail: v.singh@tamu.edu)
}

0.89 billion by 2021 (ref. 7). Although the projected share is only about $4 \%$ of the global UAV market ( $\$ 21.47$ billion), it has the potential to transform many sectors including agriculture, given India's continued growth in the information technology (IT) sector. Globally, $44 \%$ of the countries do not have any regulatory framework on UAVs as of February 2019 (Figure 1). Twelve countries $(6 \%)$ have banned UAV operations in their domain. However, nearly 97 countries (50\%) have already established regulatory guidelines. In India, the Indian Space Research Organisation (ISRO) has been utilizing satellite remote sensing data for Crop Acreage and Production Estimation (CAPE) since 1988 (ref. 8). Later, Forecasting Agricultural output using Space, Agro-meteorological and Land-based observations (FASAL) project utilized econometric and weather-based techniques for in-season yield forecasts ${ }^{9}$. Despite the success of these projects, the spatial resolution of satellite data $(\sim 20 \mathrm{~m})^{10}$ was not sufficient for site-specific studies and could not provide a measure on actual crop acreage until the Department of Agriculture or the Indian Council of Agricultural Research (ICAR) estimates were released. UAVs could assist in providing more information on segmentation of land. However, previously organizations and individuals could not utilize UAVs in research and development due to a lack of comprehensive regulations. The recent revision of the UAV/drone policy in India ${ }^{11}$ may help utilize this technology to its full potential. We believe that the recent changes in the drone policy may positively impact research and development efforts in agriculture, service and other sectors. This short review critically examines the current regulations in India and their impact on 


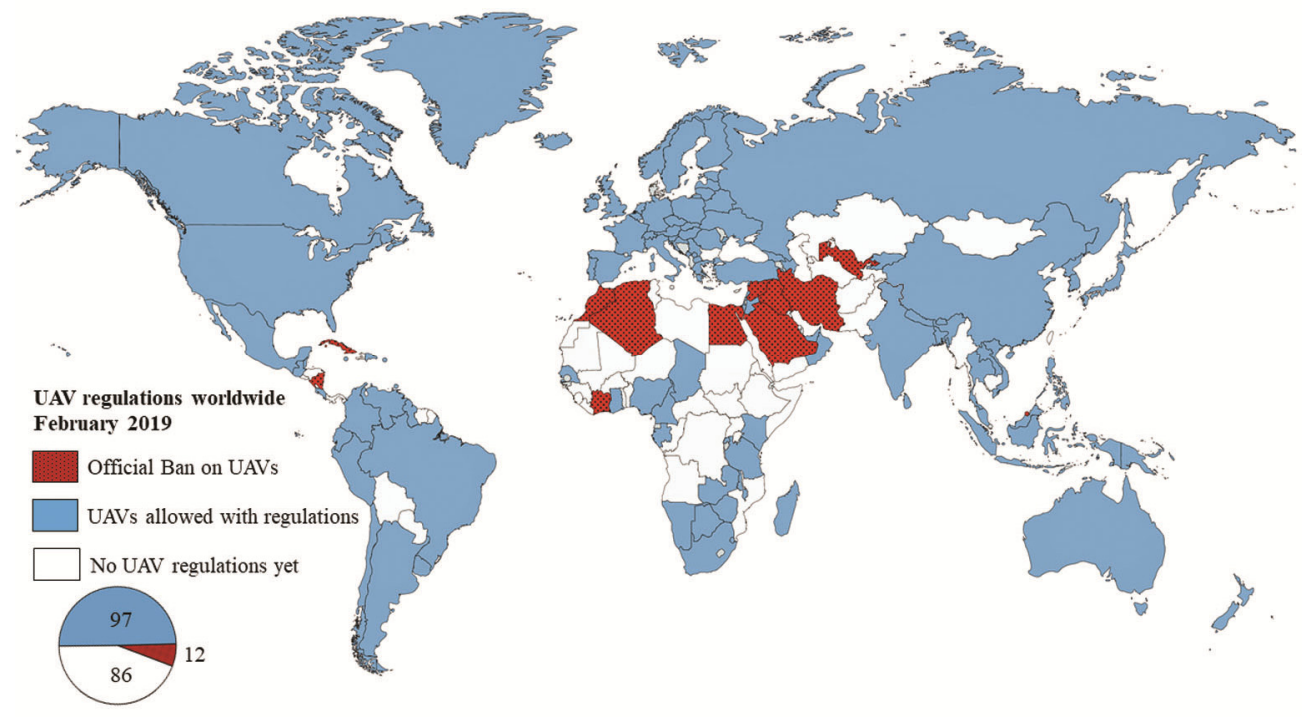

Figure 1. Regulations on the use of unmanned aerial vehicles (UAVs) worldwide as of February 2019. The map was compiled based on information gathered from the Global UAV Regulations Database available at https://droneregulations. info/index.html, and Drone Laws database available at https://uavcoach.com/.

general UAV usage, with particular focus on agricultural applications.

\section{Policy review}

The Directorate General of Civil Aviation (DGCA), India, frames policies for drone/small UAV use in India. The recent policy (05-13/2014-AED Vol. IV) advertised on 27 August 2018 was effective from 1 December 2018 (ref. 11). These civil aviation requirements are applicable to all Civil Remotely Piloted Aircraft Systems, which are controlled from a remote pilot station. DGCA categorized drones/UAVs into five groups based on their total weights. Nano $(250 \mathrm{~g})$ and micro $(250 \mathrm{~g}-2 \mathrm{~kg})$ drones are smaller UAVs generally used by hobbyists for recreational activities or photographers ${ }^{12,13}$. Mini UAVs $(2-25 \mathrm{~kg})$ and small UAVs $(25-150 \mathrm{~kg})$ are most commonly used for commercial applications, such as, landscaping, mining, advertisements, soil/irrigation mapping and crop yield assessments ${ }^{14,15}$. In agriculture, UAVs with total weight of $2-25 \mathrm{~kg}$ (including sensors) have been used more frequently for studying biotic and abiotic stress conditions of plants and other applications ${ }^{16,17}$. Large UAVs with total weight of more than $150 \mathrm{~kg}$ can be utilized for disaster relief operations and commercial applications such as small goods delivery. These groupings by DGCA allow a wide range of options and more flexibility with UAVs compared to several other countries (Table 1). Except nano drones, all UAVs require DGCA registration and unique identification number (UIN) before operation. The policy of registration at the time of purchase by the manufacturer itself may help in easing the system. However, currently, all customers are required to register their UAVs post-purchase through a Digital Sky Platform.
The requirements for the issue of UIN is governed by the nature of ownership of the UAVs. In general, ownership is restricted to Indian nationals, Central or State Government agencies, corporate houses with substantial control vested in Indian nationals, and companies that have registered outside of India but have leased UAVs to government agencies. These ownership guidelines are framed for security reasons and to avoid legal repercussions. With the current regulations, foreign individuals cannot own or operate UAVs in Indian soil. These restrictions would primarily affect foreign photographers, drone service providers, and those in the entertainment industry. India is a major tourist destination and attracts the overseas film industry to capture her historical and cultural diversity. The current restrictions on UAVs might limit such activities. Moreover, Indian agriculture suffers from lack of technological advances. The current ownership restrictions may discourage overseas experts from providing their services and trainings during the initial phase of the UAV boom expected in the next few years. Contrary to this, nationality is not the criteria for obtaining UAV license in countries such as USA, Australia and Singapore ${ }^{18-20}$. It is expected that relaxation of guidelines for foreign nationals and organizations may facilitate the infusion of technical expertise and assist with wider application of UAVs in India.

The revised UAV policy of India requires that all pilots obtain Unmanned Aircraft Operator Permit (UAOP) before operations. However, remote pilots flying nano UAVs operating below $50 \mathrm{~m}$ amsl (AGL), and micro UAVs operating below $60 \mathrm{~m}$ AGL are exempt from the requirement of UAOP. This provides some flexibility to hobbyists and photographers, though they are still required to intimate local police stations or air traffic service (ATS) units prior to flight operations. This 
GENERAL ARTICLES

Table 1. Requirements/regulations governing use of UAVs in selected countries ${ }^{\mathrm{a}}$

\begin{tabular}{|c|c|c|c|c|c|}
\hline Characteristics & $\begin{array}{c}\text { India } \\
(\mathrm{DGCA})\end{array}$ & $\begin{array}{l}\text { Singapore } \\
\text { (CAAS) }\end{array}$ & $\begin{array}{l}\text { United States of } \\
\text { America (FAA) }\end{array}$ & $\begin{array}{l}\text { China } \\
\text { (CAAC) }\end{array}$ & Australia (CASA) \\
\hline Effective policy & December 2018 & December 2017 & August 2016 & June 2017 & July 2018 \\
\hline Registration & $\mathrm{UAV}>250 \mathrm{~g}$ & $\mathrm{UAV}>250 \mathrm{~g}$ & $\mathrm{UAV}>250 \mathrm{~g}$ & $\mathrm{UAV}>250 \mathrm{~g}$ & $\mathrm{UAV}>250 \mathrm{~g}$ \\
\hline Ownership requirement & Indian citizenship & Anyone & Anyone & Anyone & Anyone \\
\hline \multirow{5}{*}{$\begin{array}{l}\text { UAV classifications for } \\
\text { civilian use }\end{array}$} & $250 \mathrm{~g}$ (nano) & $250 \mathrm{~g}$ & $250 \mathrm{~g}$ & $250 \mathrm{~g}$ & $100 \mathrm{~g}$ (micro) \\
\hline & $250-2 \mathrm{~kg}$ (micro) & 7 kg (recreational/ & 25 kg (Part 107; & $250 \mathrm{~g}-7 \mathrm{~kg}$ & $100 \mathrm{~g}-2 \mathrm{~kg}$ (very small) \\
\hline & $2-25 \mathrm{~kg}(\mathrm{mini})$ & research) & Section 336) & $7-116 \mathrm{~kg}$ & $2-25 \mathrm{~kg}$ (small) \\
\hline & $25-150 \mathrm{~kg}$ (small) & $7-25 \mathrm{~kg}$ (non-recreational/ & & $>116 \mathrm{~kg}$ & $25-150 \mathrm{~kg}$ (medium) \\
\hline & $>150 \mathrm{~kg}$ (large) & non-research) & & & $>150 \mathrm{~kg}$ (large) \\
\hline $\begin{array}{l}\text { UAV weight limit for } \\
\text { recreational/ research } \\
\text { purpose }\end{array}$ & NA & $7 \mathrm{~kg}$ & $25 \mathrm{~kg}$ & $116 \mathrm{~kg}$ & $25 \mathrm{~kg}$ \\
\hline Speed limit & NA & NA & $161 \mathrm{kmph}$ & $100 \mathrm{kmph}$ & NA \\
\hline Altitude limit (AGL/AMSL) ${ }^{\mathrm{c}}$ & $120 \mathrm{~m} \mathrm{AGL}$ & $60 \mathrm{~m}$ amsl & $120 \mathrm{~m} \mathrm{AGL}$ & $120 \mathrm{~m} \mathrm{AGL}$ & $120 \mathrm{~m} \mathrm{AGL}$ \\
\hline Aerodrome distance limit & $>5 \mathrm{~km}$ & $>5 \mathrm{~km}$ & $>8 \mathrm{~km}$ & $\begin{array}{l}\text { No flying zones } \\
\text { restrictions }\end{array}$ & $>5.5 \mathrm{~km}$ \\
\hline Permit requirement & $\begin{array}{l}\text { Permit required if } \\
\mathrm{UAV}>2 \mathrm{~kg} \\
\text { Permit required if } \\
\text { nano UAV at }>15 \mathrm{~m} \\
\mathrm{AGL} \text { or micro UAV } \\
\text { at }>60 \mathrm{~m} \mathrm{AGL}\end{array}$ & $\begin{array}{l}\text { Permit required if } \\
\text { UAV }>7 \mathrm{~kg} \text { or } \\
>200 \text { ams1 } \\
\text { Activity permits: } \\
\text { Class } 1 \text { permit } \\
\text { (non-recreational/ } \\
\text { non-research) } \\
\text { Class } 2 \text { permit } \\
\text { (recreational/research) }\end{array}$ & $\begin{array}{l}\text { Permit required } \\
\text { under Part } 107 ; \\
\text { no permit required } \\
\text { for Section } 336\end{array}$ & $\begin{array}{l}\text { Permit required } \\
\text { if } U A V>7 \mathrm{~kg} \text { or } \\
\text { commercial } \\
\text { purpose. } \\
\text { UAV }>116 \mathrm{~kg} \\
\text { requires } \\
\text { pilot license }\end{array}$ & $\begin{array}{l}\text { Permit required if } \\
U A V>2 \mathrm{~kg}\end{array}$ \\
\hline $\begin{array}{l}\text { Aerial spraying permission } \\
\text { under research category }\end{array}$ & No & No & $\begin{array}{l}\text { No }(\text { Part 107) })^{\mathrm{b}} \\
\text { Yes }(\text { Part 137) }\end{array}$ & Yes & No \\
\hline
\end{tabular}

${ }^{a}$ DGCA; Director General of Civil Aviation, India, CAAS; Civil Aviation Authority of Singapore, FAA; Federal Aviation Administration, USA, CAAC; Civil Aviation Administration of China, CASA; Civil Aviation Safety Authority, Australia.

${ }^{b}$ FAA Part 107 governs regulations for recreation or commercial applications including research. Section 336 regulates model aircraft for hobby or recreation only. FAA Part 137 regulates agricultural aircraft operations.

${ }^{\mathrm{c}}$ AGL, Above ground level; AMSL, Above mean sea level.

flexibility, coupled with low pricing, is expected to fuel the use of UAVs in this sector. The application of UAVs for research, however, would be limited for research purposes because of payload limitations, which are typically $20-30 \%$ of the total weight of the system ${ }^{3}$. The payload capacity governs the type of sensor that could be used on the platform. Other well-known technical challenges associated with smaller UAVs include insufficient engine power, short flight duration, difficulties in maintaining flight altitude, and aircraft stability and maneuverability in winds and turbulence ${ }^{21}$. Although many agricultural drones fall in the Micro UAV category, their weights may exceed the prescribed range after equipping them with sensors. This means that UAVs for precision agriculture research would require UAOP.

One of the requirements for obtaining UAOP is appropriate training in UAV operations. A five-day training has been specified, which ranges from basic principles of UAV to flight simulations ${ }^{11}$. Training curriculum is intensive and well organized. However, only 23 centres or areas have been identified for testing or demonstration of UAVs across the country. This number is low given the expected demand in India, with high thrust from researchers and commercial houses for flight licenses. Australia's Civil Aviation Safety Authority (CASA) provides trainings to applicants through $>1300$ approved training organizations that hold Remote Operator Certificate $(\mathrm{ReOC})^{19}$. However, certified pilots can only fly through these certified operators with valid ReOC. Certified pilots, in general, are employed by certified operators (with ReOC), just like the commercial aviation industry. In the US, Federal Aviation Administration (FAA) governs regulations for recreation or commercial applications of small UAVs including research under Part 107 (ref. 20). Several online training modules have been designed by third party institutions in association with the FAA. Moreover, various programmes and courses have been introduced in universities to provide theoretical and operational training to students and staff on UAVs. The FAA conducts online tests throughout the year via 684 test centres and issues UAV flight licenses ${ }^{20}$. These arrangements benefited the commercial and research institutions in the US, which is evident from the research explorations in the recent past. We believe that India can accelerate the pace of scientific research on UAVs by establishing an online system for training and licensing 


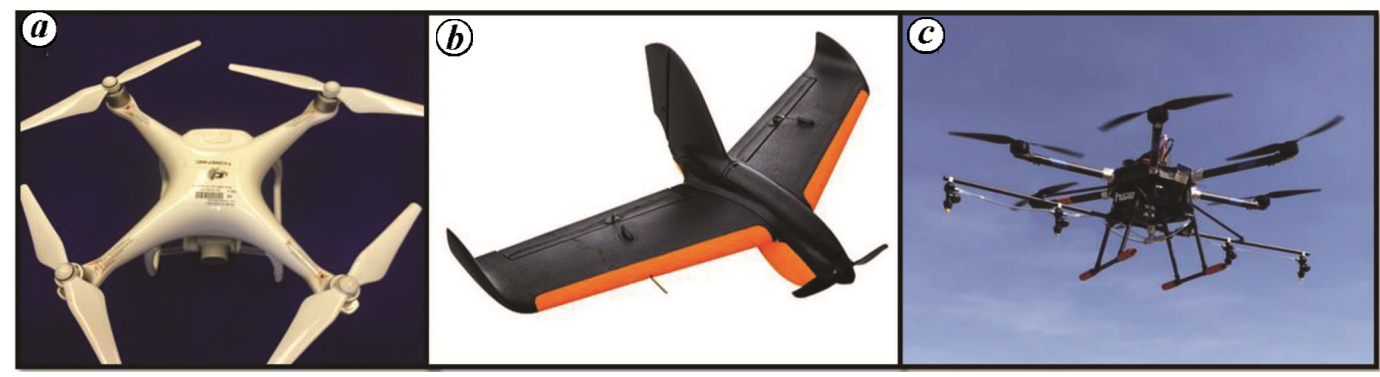

Figure 2. Notable UAV systems available in the market: (a) Rotary wing UAV (DJI Phantom 4), (b) Fixed Wing UAV (Sentera Phoenix 2) and (c) Spray UAV (HSE V6A)

the use of UAVs. Operational flight training/testing can also be made available by each airport facility or their extension centres.

The UAV flights are generally subject to the visual line of sight (VLOS) restrictions ${ }^{11,18-20,22}$. However in Australia, CASA provides options to fly UAVs outside the VLOS by obtaining an Aircraft Radio Operators License (AROC). This provision is not yet made available by DGCA. We believe that existing VLOS restrictions may not affect or restrict research operations in agriculture or urban mapping due to short flight distances, but may pose challenges to monitoring floods and other natural disasters as well as UAV-based delivery systems. The operating restrictions of DGCA also require that UAVs should not be flown within $5 \mathrm{~km}$ radius from the perimeter of major airports and $3 \mathrm{~km}$ from the perimeter of small airports. Given the speed of UAVs, these distance restrictions may not be sufficient to avoid collision or any mishap in case of malfunction in the drone system. For example, the DJI Phantom 4 Pro (DJI, Shenzhen, China 518057) drone, which weighs $1388 \mathrm{~g}$, can travel at a speed of $72 \mathrm{kmph}$ and covers $3 \mathrm{~km}$ distance in $2.5 \mathrm{~min}$ and $5 \mathrm{~km}$ in $4 \mathrm{~min}$. This window is too short for implementing any contingency management plan. The malfunctioned UAV may go out of VLOS very soon if the flight area is covered by high rise buildings or trees. Moreover, DGCA did not consider the size/weight of UAVs while framing distance restriction guidelines. For instance, large UAVs $(>25 \mathrm{~kg}$ ) can fly even at higher speeds as they can have bigger motor and greater battery capacity. In the US, distance restrictions from the nearby airport is considerably higher $(8 \mathrm{~km})$, along with a weight restriction of UAVs $(<25 \mathrm{~kg})$ under the Part 107 authorization (Table 1). In China, DJI UAVs are programmed not to take off in No-Flying Zones (NFZ) like airports/public places and for other brand UAVs, operators are required to follow NFZ regulations.

We suggest that speed limit guidelines are instituted on UAV flights, particularly when used near airports. Speed restrictions can be established at the manufacturing end to promote safer flights. In general, 20-30 kmph UAV cruzing speed is sufficient for most of the operations related to photography and imaging ${ }^{13}$. For precision agriculture, researchers have operated UAVs at $9 \mathrm{kmph}$ for mapping of weeds ${ }^{4}$, and $14 \mathrm{kmph}$ for drought stress evaluations in soybean ${ }^{16}$. In general, lower UAV speeds are preferred for better image resolution. Moreover, recent UAV usage trends show that rotary wing UAVs (e.g. Figure $2 a$ ) are used more often compared to fixed wing UAVs (e.g. Figure $2 b)^{23}$ as the former can hover on the target for precise data collection. Rotary wing UAVs can fly at lower speeds with low turning radius, assist in high resolution imagery and aerial spray applications (e.g. Figure $2 c$ ). Currently, aerial pesticide spraying through UAVs is only permitted in China (Table 1). However, in the US, aerial pesticide application license can be obtained separately under FAA Part 137, which governs the regulations of agricultural aircraft operations. In the absence of aerial pesticide licenses under current categories, there is limited research focus on developing aerial systems for pest management applications. Most of the on-going efforts are oriented towards detection and mapping of diseases-pests in crop fields. Therefore, we suggest aerial pesticide application permissions in India to push manufacturers to invest heavily for technological advances in agriculture.

Other policy guidelines like maintaining a flight distance from people, restricting flights to only during daylight and requiring permissions before flights are comparable to regulations framed by other countries. However, it is worth to note that India has specific requirements of GPS and return-to-home (RTH) functionality enabled UAVs (except nano category). In case of malfunctioning, RTH enabled UAVs/drones can return to the original spot. Moreover, GPS functionality can help in tracking the UAV/drone even if it goes beyond prescribed VLOS. Apart from this, a well thought 'No Takeoff' (NPNT) policy would help in easing the authorization process. The UAV operators are required to register and fly through Digital Sky Platform app. This is a unique feature where flight permission can be granted through mobile app but UAV may not be able to takeoff through Digital Sky Platform in case of unauthorized flight. Some of these guidelines and regulations are more user-friendly than that of other countries in terms of safety and efficiency. However, fully automated UAVs have additional functions which add to safety and operation handling. Automated UAVs are equipped with obstacle 
detection and collision avoidance technology $\mathrm{y}^{24,25}$. For research purposes, automation is much needed to ensure consistent and accurate results. Automated UAV systems work based on algorithms that guide flight path and can assist in calibration for precise data collection. Automated UAV systems fly according to a pre-determined flight path based on the flight planner and would not require pilot skills to keep it under range. Flight planner is necessary for orthomosaicking and consistent overlapping of images ${ }^{26}$. Automation systems may not be feasible for all UAV categories intended for photography or recreational activities, but it can be made mandatory for flights near sensitive areas or in UAVs $>2 \mathrm{~kg}$ gross weight. Therefore, automation would not only help in improving quality data collection but would also add to the safety.

\section{Conclusion}

We foresee that the current DGCA restrictions and guidelines on the operation of UAVs would not only affect commercial applications, but also govern the pace of research and development in machine vision capabilities. Farmers in developed countries are embracing this technology for cost saving and to increase yield and profit. In India, UAVs equipped with sensors have incredible potential for improving crop management even in a small-scale farm, and open up new opportunities for disease, insect pest and weed monitoring and management if DGCA policies provide sufficient flexibility for research and development.

1. Hunt Jr, E. R. and Daughtry, C. S., What good are unmanned aircraft systems for agricultural remote sensing and precision agriculture? Int. J. Remote Sens., 2018, 39, 5345-5376.

2. Zhang, C. and Kovacs, J. M., The application of small unmanned aerial systems for precision agriculture: a review. Precis. Agric., 2012, 13, 693-712.

3. Nebiker, S., Annen, A., Scherrer, M. and Oesch, D., A lightweight multispectral sensor for micro UAV-opportunities for very high resolution airborne remote sensing. Int. Arch. Photogramm. Remote Sens. Spat. Inf. Sci., 2008, 37, 1193-1199.

4. Gao, J. et al., Fusion of pixel and object-based features for weed mapping using unmanned aerial vehicle imagery. Int. J. Appl. Earth Obs. Geoinf., 2018, 67, 43-53.

5. Bai, G., Jenkins, S., Yuan, W., Graef, G. L. and Ge, Y., Fieldbased scoring of soybean iron deficiency chlorosis using RGB imaging and statistical learning. Front. Plant Sci., 2018, 9, 1002; doi:10.3389/fpls.2018.01002.

6. Hague, T., Marchant, J. A. and Tillett, N. D., Ground based sensing systems for autonomous agricultural vehicles. Comput. Electron. Agric., 2000, 25, 11-28.

7. BIS research, Global Unmanned Aerial Vehicles Market 2021, BIS Res., 2018; https://bisresearch.com/industry-report/globalunmanned-aerial-vehicles-market-2021.html (accessed on 18 September 2018).

8. ISRO, Agriculture and Soil. Indian Space Research Organisation, India, 2019; https://www.isro.gov.in/earth-observation/agricultureand-soils (accessed on 6 March 2019).

9. Parihar, J. S. and Oza, M. P., FASAL: an integrated approach for crop assessment and production forecasting. Agriculture and
Hydrology Applications of Remote Sensing. In Proceedings of SPIE, Goa, India, 2006, 6411, 641101-641113; doi:10.1117/ 12.713157.

10. MNCFC, Forecasting Agricultural output using Space, Agrometeorology and Land based observations. Mahalanobis National Crop Forecast Centre, India, 2019; http://www.ncfc.gov.in/ about fasal.html (accessed on 6 March 2019).

11. DGCA, Civil Aviation Requirements. Director General of Civil Aviation, India, Policy F. No. 05-13/2014-AED, 2018, vol. 4, pp. 1-24; http://www.dgca.nic.in (accessed on 10 September 2018).

12. Sundqvist, L., Cellular controlled drone experiment: evaluation of network requirements. MSc thesis, Aalto University, Helsinki, Finland, 2015, pp. 1-61.

13. Chen, S., The regulation of the recreational use of 'Drones' for aerial photography and videography: comparing Singapore's unmanned aircraft act with other legislation, Singapore Law Rev., 2015, 33, 55-92.

14. Siebert, S. and Teizer, J., Mobile 3D mapping for surveying earthwork projects using an unmanned aerial vehicle (UAV) system. Automat. Constr., 2014, 41, 1-14.

15. Shakhatreh, H. et al., Unmanned aerial vehicles: a survey on civil applications and key research challenges. arXiv Preprint, 2018, arXiv: 1805.00881

16. Kaler, A. S., Ray, J. D., Schapaugh, W. T., Asebedo, A. R., King, C. A., Gbur, E. E. and Purcell, L. C., Association mapping identifies loci for canopy temperature under drought in diverse soybean genotypes. Euphytica, 2018, 214, 135.

17. Watts, A. C., Ambrosia, V. G. and Hinkley, E. A., Unmanned aircraft systems in remote sensing and scientific research: classification and considerations of use. Remote Sens., 2012, 4, 1671-1692.

18. CAAS, Regulations on unmanned aircraft operations. Civil Aviation Authority of Singapore, 2018; https://www.caas.gov.sg/ (accessed on 18 September 2018).

19. CASA, Flying drones/automated aircraft in Australia. Civil Aviation Safety Authority, Australia, 2018; https://www.casa.gov.au (accessed on 10 September 2018).

20. FAA, Unmanned Aircraft Systems, Federal Aviation Administration, USA, 2018; https://www.faa.gov/uas/ (accessed on 10 September 2018).

21. Hardin, P. J. and Hardin, T. J., Small-scale remotely piloted vehicles in environmental research. Geogr. Compass., 2010, 4, 1297-1311.

22. CAAC, Unmanned Aerial Vehicle Regulations. Civil Aviation Administration of China, 2018; http://www.caac.gov.cn/en/ (accessed on 10 September 2018).

23. Anonymous, Commercial Drone Industry trends. Drone Deploy, 2017; https://blog.dronedeploy.com/commercial-drone-industrytrends-aae2010ff349 (accessed on 27 September 2018).

24. Israelsen, J., Beall, M., Bareiss, D., Stuart, D., Keeney, E. and van den Berg, J., Automatic collision avoidance for manually teleoperated unmanned aerial vehicles. In Proceedings of Robotics and Automation (ICRA), IEEE International Conference, Hong Kong, China, 2014, IEEE 6638-6643.

25. DJI, 5-Direction of Obstacle Detection, Dà-Jiāng Innovations (DJI), 2018; https://www.dji.com/phantom-4-pro (accessed on 25 September 2018).

26. Raczynski, R. J., Accuracy analysis of products obtained from UAV-borne photogrammetry influenced by various flight parameters, Master's thesis, Norwegian University of Science and Technology, Trondheim, 2017; https://brage.bibsys.no/xmlui/handle/ $\underline{11250 / 2452453}$.

Received 13 October 2018; revised accepted 13 March 2019

doi: $10.18520 / \mathrm{cs} / \mathrm{v} 117 / \mathrm{i} 1 / 25-29$ 